\title{
Anomalous origin of both coronary arteries from the pulmonary trunk
}

\author{
BARRY R KEETON, DANIEL J M KEENAN, JAMES L MONRO \\ From the Department of Paediatric Cardiology, The Wessex Cardiac and Thoracic Centre, The Western Hospital, \\ Southampton
}

SUMMARY We report what appears to be the first case diagnosed in life at cardiac catheterisation of anomalous origin of both of the coronary arteries from the pulmonary trunk, and its attempted surgical correction.

The incidence of anomalous origin of the total coronary circulation from the pulmonary trunk is unknown, but it is a rare condition having been reported, on the basis of postmortem examination, in 13 cases $^{1-3}$ and suspected, at operation, in one further instance. ${ }^{4}$ It has occurred as an isolated lesion ${ }^{1-3}$ and also in association with other, structural intracardiac anomalies..$^{4-6}$ Alone, it is held, generally, to be incompatible with survival beyond a few weeks but survival to 7 years has been reported in a case where other intracardiac defects were present. ${ }^{4}$ It has not, to our knowledge, been previously diagnosed during life.

\section{Case report}

A 5 month old female infant was referred to the Wessex Cardiac and Thoracic Centre after the discovery of a mediastinal shadow on chest radiography. She was the only live child of apparently healthy parents whose first child was stillborn and whose second child died in the neonatal period having been born prematurely. No necropsies were performed in these cases. This pregnancy had been complicated by vomiting and urinary tract infection. Normal delivery of a 3.8 $\mathrm{kg}$ baby (25th centile) occurred at full term. Apgar scores were normal and the neonatal period was uneventful. An anal skin tag was noted at birth and she was admitted to hospital for excision of this lesion at the age of $4 \frac{1}{2}$ months. It was during this admission that concern about her heart arose and she was referred to the cardiac unit for assessment.

The parents reported that she had always breathed rapidly and expressed concern over her weight gain; weight on admission was $4.8 \mathrm{~kg}$ ( $3 \mathrm{rd}$ to 10 th centile). On examination she was pale with cool peripheries.
There was no cyanosis or finger clubbing. Peripheral oedema and venous distension were absent. All pulses were palpable and systolic blood pressure was equal in the arms and legs at $100 \mathrm{mmHg}$. There was diffuse increase in apical pulsation but no thrills were palpable. The first heart sound was normal, the second heart sound was closely split with a loud pulmonary component. There was a soft ejection systolic murmur at the left sternal border but no diastolic murmur. The liver was enlarged $3 \mathrm{~cm}$ below the right costal margin. The respiratory rate was 50 per minute and there was some intercostal and subcostal recession with flaring of the alae nasi, but on auscultation there was good air entry with no adventitial sounds. There was a renal mass in the left loin, later confirmed to be a duplex kidney.

Chest radiography disclosed minor cardiac enlargement. The right heart border was completely obscured by shadowing in the right lung field which, on radiological screening, was shown to be a collapsed right middle lobe and a thymic shadow. There was increased venous marking in both lungs. Electrocardiography showed sinus rhythm with a mean frontal QRS axis of $+30^{\circ}$. There was left ventricular hypertrophy and left sided ST segment and T wave abnormalities. Prominent $Q$ waves were seen in standard leads III and aVF. Echocardiography showed normal intracardiac anatomy. The left ventricle was dilated and poorly functioning. The left atrium was enlarged (LA/Ao ratio 1.5 ).

Physiotherapy failed to achieve re-expansion of the right middle lobe though digoxin and diuretics resulted in improvement of the tachypnoea and diminution of the hepatomegaly. Three weeks after admission, cardiac catheterisation was performed and this showed no intracardiac shunts but right ventricu- 
lar $(55 / 0 \mathrm{mmHg}$, EDP $7.5 \mathrm{mmHg})$ and pulmonary artery $(55 / 23 \mathrm{mmHg}$, mean $42 \mathrm{mmHg}$ ) pressures were raised to $61 \%$ of systemic arterial pressure (aorta $90 / 60$ $\mathrm{mmHg}$, mean $66 \mathrm{mmHg}$ ). Left ventricular pressure had a high end-diastolic component $(90 / 0 \mathrm{mmHg}$, EDP $35 \mathrm{mmHg}$ ). Left ventricular angiography showed a large dilated chamber with global impairment of contactility and a low ejection fraction. There was mild mitral regurgitation. Ascending aorta angiography (Fig. 1) showed an apparently normal left sided aorta and aortic valve with no regurgitation. The brachiocephalic branches filled normally but no coronary arteries were visualised, and therefore a pulmonary arteriogram was performed (Fig. 2). This showed the two distinct origins of the coronary arteries arising from the pulmonary artery, the left coronary giving off the anterior descending coronary artery and a normal pattern of distribution.

Later the same day, correction of the cardiac lesion was carried out using cardiopulmonary bypass with hypothermic arrest $\left(18^{\circ} \mathrm{C}\right) .^{7}$ An aortopulmonary window $4.5 \mathrm{~mm}$ in diameter was fashioned and a pericardial patch was then sutured inside the pulmonary arteries in such a manner as to roof over the two coronary orifices and the aortopulmonary window, with the result that blood from the aorta could flow down the two coronary arteries. The child was rewarmed on cardiopulmonary bypass and after some initial difficulty, bypass was discontinued with the help of infusions of dopamine and adrenaline. High left atrial pressures of 20 to $25 \mathrm{mmHg}$ were required to achieve

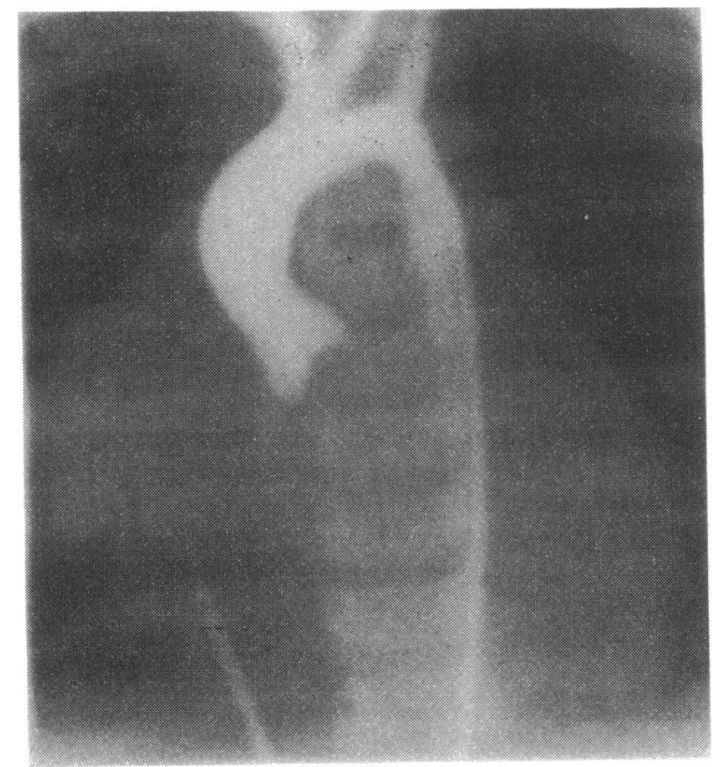

Fig. 1 Ascending aortogram showing the absence of cononary arteries. satisfactory systemic pressures. Pressures at the end $\stackrel{\mathbb{D}}{\rightleftharpoons}$ of the procedure were systemic $100 \mathrm{mmHg}$, right $c$ atrial $15 \mathrm{mmHg}$, right ventricular $30 \mathrm{mmHg}$, and left $\vec{\Rightarrow}$ atrial $25 \mathrm{mmHg}$.

The child was returned to the intensive care unit on a dopamine infusion and, despite apparently adequate arterial pressure, there was evidence of low cardiac output with oliguria and cold peripheries. On regaining consciousness a reasonably stable state was i maintained with the aid of dopamine and sodium nit- $\overrightarrow{0}$ roprusside infusions, but urine output remained unsatisfactory and peritoneal dialysis was instituted $\vec{c}$ on the third postoperative day to correct fluid overload. Deterioration was progressive and death occurred 100 hours after operation.

\section{PATHOLOGY}

A postmortem radiological examination of the heart after injection of dilute barium into the aortic root $\frac{1}{5}$ showed filling of both coronary arteries from the aorta though the right coronary filled better than the left.

On gross examination, intracardiac anatomy was normal. The left and right coronary orifices were just $\vec{\emptyset}$ above the left and right posterior cusps of the pulmonary artery, respectively. There appeared to be a satis- : factory communication between the aortic root and each coronary artery via the aortopulmonary window and pericardial patch, though the patch may have $\stackrel{D}{\circ}$ encroached somewhat upon the origin of the left $\stackrel{\circ}{\varnothing}$ coronary artery. The patch did not obstruct the pulmonary artery. The left ventricle was very dilated.

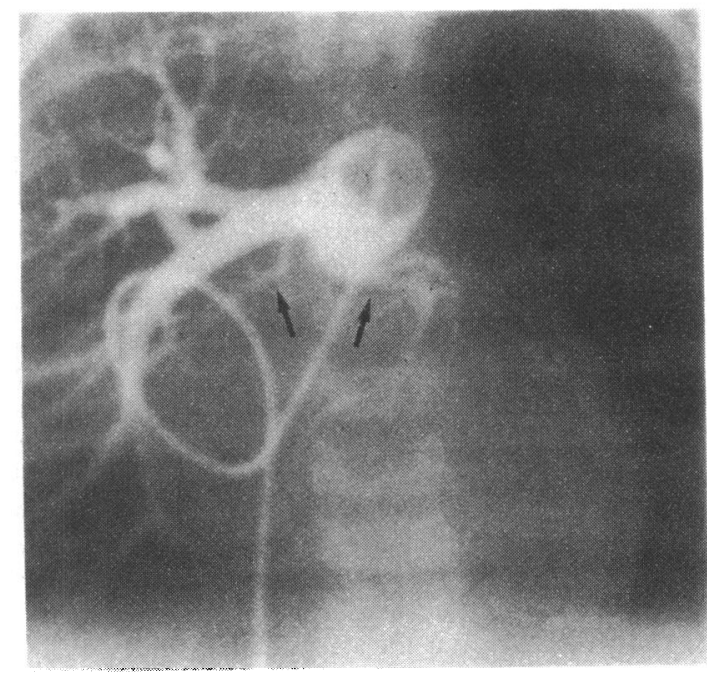

Fig. 2 Pulmonary arteriogram shows both coronary arteries (arrowed) arising from the pulmonary trunk. The catheter has been coiled in the right atrium to maintain a stable position of the inflated balloon during angiography. . 
Histological examination of the left ventricular myocardium showed marked ischaemic changes, with extensive fibrosis.

\section{Discussion}

In an infant with a dilated poorly functioning left ventricle but an otherwise structurally normal heart the differential diagnosis includes primary myocardial disorder, and also abnormal coronary arterial supply, most commonly anomalous origin of the left coronary artery. Diagnosis in this latter group is by left ventriculography and aortography. From the paucity of reports of such cases it appears that origin of both coronary arteries from the pulmonary artery is a rare condition, particularly as an isolated anomaly. It is possible, however, that a certain number of such cases escape diagnosis because of lack of awareness of the anomaly. In our patient it would have been very easy to overlook the absence of opacification of the coronary arteries on the aortogram or to attribute this to poor catheter positioning in the aortic root. This was indeed our initial reaction when viewing the video recordings and it was only after the developed cineangiogram was examined that the correct diagnosis was suspected and confirmed by pulmonary arteriography. In the postmortem examination of infants dying from apparent primary myocardial abnormality it would be equally easy to overlook the abnormal origin of the coronary arteries unless both coronary ostia are carefully looked for. That anomalous origin of the coronary artery may be readily overlooked in the presence of other intracardiac anomalies has recently been highlighted by Wilcox and co-workers. ${ }^{8}$ Careful attention to the origin of coronary artery supply is mandatory in infants with impaired left ventricular function.

There are no previous reports of surgical correction of this anomaly though experience is growing in the correction of the commoner lesion, anomalous origin of the left coronary artery from the pulmonary artery, which produces a similar clinical picture. ${ }^{910}$ The surgical technique of fashioning an aortopulmonary window, as was used in this case, was first reported by Hamilton et al. ${ }^{11}$ for the correction of anomalous left coronary artery. This technique is an ideal method of correcting an anomalous left coronary artery, and we have used it successfully in infancy. From the present experience it appears satisfactory in cases where both coronary arteries are anomalous, though the technical difficulties may be greater. A satisfactory surgical outcome will depend not only on adequate reperfusion of the myocardium but also on satisfactory ventricular performance before operation. It was almost certainly the pre-existing profound impairment of ventricular function which led to an unfavourable outcome in our patient. Earlier diagnosis would have offered a better chance of a successful surgical result.

It is difficult to understand why our patient presented so late, since similar cases, including the three reported instances of origin of a single coronary artery from the pulmonary artery, 356 have succumbed after time intervals of between three and 33 days. In the case described by Feldt et al.${ }^{4}$ perfusion of the single coronary artery at high pressure was maintained by the associated cardiac defect, until this was corrected at operation, when death rapidly ensued. The pulmonary artery pressure in our patient was considerably raised above normal $(55 / 23 \mathrm{mmHg})$ and it is possible that the normal fall in pulmonary vascular resistance was delayed, permitting survival until 173 days.

\section{References}

1 Roberts WC. Anomalous origin of both coronary arteries from the pulmonary artery. Am $\mathcal{f}$ Cardiol 1962; 10: 595-600.

2 Blake HA, Manion WC, Mattingly TW, Baroldi G. Coronary artery anomalies. Circulation 1964; 30: 927-40.

3 Colmers RA, Siderides CI. Anomalous origin of both coronary arteries from pulmonary trunk. Myocardial infarction in otherwise normal heart. Am F Cardiol 1963; 12: 263-9.

4 Feldt RH, Ongley PA, Titus JL. Total coronary arterial circulation from pulmonary artery with survival to age of seven. Report of case. Mayo Clin Proc 1965; 40: 539-43.

5 Ogden JA. Origin of a single coronary artery from the pulmonary artery. Am Heart $\mathcal{f}$ 1969; 78: 251-3.

6 Gonzalez-Angulo A, Reyes HA, Wallace SA. Anomalies of the origin of coronary arteries. (Special reference to single coronary artery.) Angiology 1966: 17: 96-103.

7 Manners JM. Anaesthesia for cardiac surgery. In: Norman J, Whitwam J, eds. Topical reviews in anaesthesia. vol 1. Bristol: John Wright, 1980: 179-259.

8 Wilcox WD, Hagler DJ, Lie JT, Danielson GK, Smith HC, Fulton RE. Anomalous origin of left coronary artery from pulmonary artery in association with intracardiac lesions. Report of two cases. $\mathcal{F}$ Thorac Cardiovasc Surg 1979; 78: 12-20.

9 Levitsky S, van der Horst RL, Hastreiter AR, Fisher EA. Anomalous left coronary artery in the infant. $\mathcal{F}$ Thorac Cardiovasc Surg 1980; 79: 598-602.

10 Arciniegas E, Farooki ZQ, Hakimi M, Green EW. Management of anomalous left coronary artery from the pulmonary artery. Circulation 1980; 62: 1180-9.

11 Hamilton DI, Ghosh PK, Donnelly RJ. An operation for anomalous origin of the left coronary artery. Br Heart $\mathcal{J}$ 1979; 41: 121-4.

Requests for reprints to Dr Barry R Keeton, Department of Paediatric Cardiology, The Wessex Cardiac and Thoracic Centre, The Western Hospital, Oakley Road, Southampton SO9 4WQ. 